\title{
The Impact of Bybee and Synectics Models on Creativity, Creative Problem-solving, and Students' Performance in Geometry
}

\author{
Zahra Kalantarnia ${ }^{1}$ \\ Ahmad Shahvarani semnani ${ }^{2}$ \\ Mohammad Hassan Behzadi ${ }^{3}$ \\ Mohsen Rostamy -MalKhalifeh ${ }^{4}$ \\ Mohammad Reza Mardanbeigi ${ }^{5}$
}

Journal for Educators, Teachers and Trainers, Vol. 11 (1)

https://jett.labosfor.com/

Date of reception: 15 March 2020

Date of revision: 18 June 2020

Date of acceptance: 14 August 2020

Zahra Kalantarnia, Ahmad Shahvarani semnani, Mohammad Hassan Behzadi, Mohsen Rostamy - MalKhalifeh, Mohammad Reza Mardanbeigi (2020). The Impact of Bybee and Synectics Models on Creativity, Creative Problem-solving, and Students' Performance in Geometry. Journal for Educators, Teachers and Trainers, Vol. 11(1). 68-78.

1,2,4,5 Department of Mathematics, Science and Research Branch, Islamic Azad University, Tehran, Iran. ${ }^{3}$ Department of Statistics, Science and Research Branch, Islamic Azad University, Tehran, Iran. 


\title{
Journal for Educators, Teachers and Trainers, Vol. 11 (1) \\ ISSN 1989 - 9572 \\ https://jett.labosfor.com/
}

\section{The Impact of Bybee and Synectics Models on Creativity, Creative Problem-solving, and Students' Performance in Geometry}

Zahra Kalantarnia ${ }^{1}$, Ahmad Shahvarani semnani², Mohammad Hassan Behzadi ${ }^{3}$, Mohsen Rostamy - MalKhalifeh ${ }^{4}$, Mohammad Reza Mardanbeigi ${ }^{5}$

1,2,4,5 Department of Mathematics, Science and Research Branch, Islamic Azad University, Tehran, Iran. ${ }^{3}$ Department of Statistics, Science and Research Branch, Islamic Azad University, Tehran, Iran.

Email: Zahra_kalantarnia@yahoo.com,_Shahvarani._Ahmad@yahoo.com, behzadi@srbiau.ac.ir, rostamy@srbiau.ac.ir, mrmardanbeigi@srbiau.ac.ir

\begin{abstract}
The present study aimed to investigate the effect of Bybee and Synectics on creativity, creative problem-solving, and performance of ninth-grade students in geometry. The research method was quasi-experimental with pre-test, post-test, and control group. From the entire population of the ninth-grade female students of public high schools in Tehran, three intact classrooms were selected by the cluster sampling method, each consisting of 30 students. Then, two classes were randomly assigned to two experimental groups and one control group. In addition, research instruments included Abedi's creativity test, Basadur's problem-solving creative test, and a researcher-made geometry test .In order to collect data, at first, pre-tests of performance, creativity and creative solution were performed on the subjects. After performing the patterns in the groups, post-tests of performance, creativity and creative solution were performed on the subjects. Finally, descriptive (the mean and standard deviation) and inferential ANCOVA statistics were used to analyze the data by SPSS software. The findings indicated that using the patterns of Bybee and Synectics on students' creativity, creative problem-solving, and performance in geometry were significantly more influential compared to traditional teaching methods. The use of educational patterns appropriate to the educational content will lead to the training of creative people.
\end{abstract}

Keywords: Bybee model, Synectics model, Creativity, Creative problem-solving, Geometry

\section{INTRODUCTION}

Geometric concepts are the most important issues when teaching mathematics. Different views on theories such as misconceptions, conceptual errors, mental disorders, and the lack of information are possible at almost every level. When considering these perspectives and the importance of teaching geometry, it is understandable how to overcome the problems that may arise during the process (Fyfe et al., 2015). It is worth noting that, in the conventional view of mathematics teaching, the end objective of teaching concepts is to improve students' problem-solving abilities. In this view, problem-solving equates with reaching the correct answer (Karimi, Shahvarani, \& Haghverdi, 2019).

To improve the students' awareness of problem-solving strategies, teachers are required to be informed of common problems that impede qualified mathematics education. The teachers need to be skilled in using a wide range of strategies, techniques, and activities in order to help building the prerequisite knowledge and strengthen the connection between students and a particular concept. This may include discussing, telling stories, using role-playing and visual imagery, encouraging search patterns, and using real-life examples and analyses, along with metaphors and explanations (McLaren, 2010). Furthermore, additional concepts can be learned by the development of concepts and their relationships (Gallenstein, 2013). It seems that some teaching models can 
play a role when used in a specific context within the classrooms. In the current study, Bybee and Synectics models were used since it was assumed that these two strategies would improve creativity, creative problemsolving, and performance of ninth-grade students in geometry.

Piaget's cognitive development initially consisted of exploration, invention, and discovery stages, and then was modified by Roger Bybee to constructivism. This model of teaching enhances learning outcomes for students with different cognitive levels (Walia, 2012). It was developed by Bybee (2009) and called the " $5 \mathrm{E}$ training cycle model" because each step begins with the letter "E". An unbiased teaching method has several benefits. It is learner-centered, includes more meaningful learning activities, and prevents the mere retention of information. In addition, this method absorbs and adapts information through problem-solving and information acquisition, and finally, encourages learners to promote their extracurricular activities in order to have critical thinking and ethics (Suciati, Vincentrisia, \& Ismiyatin, 2015). In the majority of the studies, the 5E Model was extensively used in international mathematics education (Bybee, 2009).

The Synectics model was the other model that was used in the current study. Low conceptual understanding is considered as one of the major problems in mathematics, in general, and in geometry, in particular, which is probably because the students' perceptions of this subject are unrelated to everyday life. Accordingly, using a Synectics model to teach geometric concepts is one possible solution to this problem. Various studies explored the use of a Synectics model to clarify and develop concepts (Heid, 2008).

The model was postulated by Gordon et al. in 1961. The process of synectics probably implies that it can join diverse and seemingly trivial elements to create new ideas about a concept. It is a creative process that works relying on one's mental capacity to discover and unite subjects in different and unrelated ways (Gordon, 1961). Among all factors, Synectics seems to play with unrelated responses. Further, this role is used to produce energy in order to solve problems and stimulate new perspectives and problems (Blissett \& Mc Grath, 1996).

It is worth mentioning that the creative problem-solving process is defined as the application of creativity to the real world, industry, organization, or the social context for problem-solving, as well as presenting and implementing solutions to complex issues. The creative problem-solving model involves a three-step process of problem finding, problem-solving, and solution execution (Basador, Graen, \& Green, 1982). Choosing and implementing an appropriate approach to the goals of each lesson require a variety of research and a comprehensive review of the benefits and limitations of traditional and active teaching models in geometry. Considering the importance of Bybee and Synectics models in geometry, the current study sought to evaluate the effects of these models on creativity, creative problem-solving, and the performance of ninth-grade students in geometry.

\section{THEORETICAL AND EMPIRICAL BACKGROUND}

Researchers have shown that math instruction is effective when students are actively involved in the learning process, thus math teachers should use interactive group activities to encourage students instead of using an explanatory teaching approach. The 5E teaching model is one approach through which students actively participate in the learning process (Runisah Hemen, \& Dahlan, 2016). The steps of the 5E learning cycle model are as follows.

1. Engage: At this point, students are stimulated by disrupting their cognitive balance or drawing their attention to real-life events.

2. Explore: At this stage, the student's experiences are used for observing, collecting data, predicting test questions, and correcting the hypotheses in order to be able to answer the questions posed in the previous step.

3. Explain: At this phase, the students provide their own observations and data that give a scientific explanation of their obtained results.

4. Elaborate: At this stage, other issues arise for students regarding using their new knowledge, providing solutions, making decisions, and reaching rational results.

5. Evaluate: Evaluation is needed to determine whether students have a correct understanding of the concepts or are able to extend their learning to other areas (Acisli, Yalem, \& Turgut, 2011).

A bulk of research has focused on this area. For instance, Demircioglu and Cagatay (2014) attempted to examine the effect of laboratory studies based on Bybee's model on the students' comprehension of chemistry. Their findings showed that using this pattern was significantly more effective on students' comprehension compared to traditional teaching models. 
In their study on the application of the learning cycle model (5E) learning with chart variations to students' creativity, Sacita et al. (2015) demonstrated that using the Bybee model would improve students' creativity.

Similarly, Tezer and Cumhur (2017) focused on the 5E teaching model and mathematical modeling without altering the main structure of the model and found that using this model had a positive impact on academic achievement and problem-solving skills, as well as the increased motivation of students for mathematics. The rhythmic pattern is designed to enhance students' creativity and creativity in problem-solving. In this model, three types of metaphors (i.e., direct analogy, personal analogy, and intense conflict) form the basis of the sequence of synectics activities. Students develop an understanding of geometric concepts and build on their new knowledge based on past life experiences.

In addition, Gordon defined synectics or metaphorical thinking based on four ideas. Creativity is important in everyday life, not just for art and improvisation. In other words, it is part of our lives in our work and leisure. Further, the creative process is not very mysterious and not limited to specific people who are familiar with the basics of creativity. Based on another idea, creative innovation is similar in all areas of empirical sciences, mathematics, and humanities. Finally, individual and group creative thinking or innovation is very similar to one another. More precisely, individuals and groups create their ideas and products in similar ways (Joyce et al., 2013). The steps of this pattern are described as follows.

1. Problem Description: At this point, the teacher encourages the students to describe the new situation.

2. Direct Analogy: A direct analogy is a simple comparison of two existents or concepts. In this comparison, not all aspects are necessarily identical. A straightforward comparison is simply made by pushing forward the conditions of a given subject or a real situation having a problem with another situation in order to present a new theory of a problem.

3. Personal Analogy: In the personal analogy, students must place themselves in other elements or feel the attributes of other elements. Simulation is the basis of personal analogy. This replication may occur with a person, plant, animal, or inanimate being.

4. Compact Conflict: It describes two contradictory words of the same subject, giving the deepest and widest insight.

5. Direct Analogy: At this stage, students select and present another direct analogy based on intense conflicts. It should be noted that there is no word on the main issue at this point.

6. Assignment Review: At this point, the teacher encourages the students to return to the main task or question and use the latest analogy with all the experiences of theorizing (Shabani \& Hassan, 2016).

In the research entitled "Using Integrated Analogy in Physics Education to Building Concept of Representation: The Way to be Great Inventor", Arifiyanti and Wahyuningish (2015) found that the innovative model and the analogies serve as useful tools for teaching, learning, and understanding abstract concepts.

Ahmad Khan and Mahmoud (2017) also examined the role of synectics in students' comprehension of geometric concepts and concluded that their comprehension and learning skills significantly increased when they were instructed according to this model. Based on the review of the related literature and to our best knowledge, no similar study has been conducted in the context like Iran in the big area of geometry using the above-mentioned models.

\section{METHOD}

Based on its purpose, the present study used a quasi-experimental design and sought to provide practical and usable findings in the field of teaching methods. In this study, a pretest-posttest with the control group was used in this regard. The study population included all ninth-grade female students of the public high schools of Tehran, Iran. In addition, three intact classes of ninth-grade female students were selected by a cluster sampling technique and each class consisted of 30 students. The two classes were randomly selected as Bybee and Synectics experimental groups, as well as the control group. Further, a researcher-made test was developed based on students' prior knowledge of geometrical concepts in order to investigate the scientific level of all students in all groups. The experimental and control groups were also tested on creativity pre-tests and creative problem-solving. Subsequently, the content of the lessons was taught by Bybee and Synectics patterns and the traditional method for experimental and control groups in six 90-minute sessions, respectively. After completing 
the sessions and activities, creativity and problem-solving tests and researcher-made performance tests were performed on all three groups and the findings were compared accordingly.

\section{Participants}

Given that geometry topics are essentially raised in the ninth grade and a considerable portion of this book is devoted to geometry, the ninth grade was selected for this research. From the population of the ninth grade female students of Tehran secondary schools, the sample of this study was randomly selected from a female public school in Tehran. Three ninth grade classrooms were selected by the cluster sampling method, each containing 30 female students (16 years old). The students in the experimental groups comprised of 6 groups of 5 and one representative were selected for each group. The curriculum based on Bybee and Synectics models prepared by the examiners was tailored and reviewed prior to the treatment.

\section{Instruments}

Abedi's creativity test was used to determine the extent of the students' creativity promotion. Abedi adopted this test based on Torrance's theory of creativity in 1984. This test had 60 items on a 3-point Likert-type scale which consists of four subtypes of fluidity, expansion, ingenuity, and flexibility. The total creativity score of each subject was between 60 and 180. The reliability of Abedi's creativity test was achieved through the test-retest method from the secondary school students of Tehran in four test sections. The reliability coefficient of the fluid fraction, initiative, flexibility, and extension was $0.85,0.82,0.84$, and 0.80 , respectively. The correlation coefficient between the total score of Torrance's test and this test was calculated to be 0.63 (Abedi, 1993). To assess the reliability of the test, Cronbach's alpha in each section was calculated as $0.83,0.86$, and 0.89 for control, Bybee, and Synectics, respectively.

Furthermore, the creative problem-solving test of Basadur was used to determine the amount of creative solution. The creative solution to the problem began with Wallace's work in 1926. However, one of the most prestigious creative problem-solving models belongs to Basadur. This test had 16 items on a 5-point Likert-type scale ranging from never, very few, sometimes, often, to very often. Questions 1, 2, 3, 4, 5, 6, 7, 9, 10, 13, 14, and 15 are scored directly, meaning that the choice of "never", "very few", "sometimes", "often", and "very often" were scored 1 to 5 , respectively. However, questions " $8,11,12$, and 16" were scored reversely. The minimum and maximum scores were 16 and 80 . The validity of this test was estimated using the concurrent validity of this test with Torrance's verbal creativity test. The findings showed that the subscales of flexibility $(\mathrm{R}=0.603, \mathrm{P}<0.1 \%)$, fluidity $(\mathrm{R}=0.596, \mathrm{P}<0.1 \%)$, and initiative $(\mathrm{R}=0.464, \mathrm{P}<0.1)$ significantly correlated with Basadur's creative problem-solving test, indicating the acceptable validity of the subject. Moreover, Cronbach's alpha for the whole test was 0.884 , representing that this test was reliable. Therefore, this ensures that all items are appropriate and there is no need to eliminate some items (Zare et al., 2014). Finally, Cronbach's alpha was calculated for control, Bybee, and Synectics sections as 0.80, 0.81, and 0.77 in order to assess the reliability of the test.

The geometry researcher-made test was used to evaluate students' learning levels. For the pre-test, 10 questions were selected, which were related to the prerequisites of the topics of the ninth-Grade Pre-formed Geometry Questions. These included five, three, and 2 easy, intermediate, and difficult questions, respectively. The posttest consisted of nine questions of the taught topics, including three, four, and two easy, intermediate, and difficult questions, respectively. Mathematics professors discussed and approved the extent to which the test questions represented the content and purpose of the research. Each test score was out of 20. The internal consistency test (split-half test) was used to evaluate the reliability of the tests in this study and its value was obtained in the following groups. The value of reliability for the pretest of control, Synectics, and Bybee groups was $0.70,0.78$, and 0.70 , respectively. The value of reliability for the posttest of control, Synectics, and Bybee groups was $0.70,0.71$, and 0.72 , respectively.

\section{Examples of topics}

The following are some examples of geometry topics in accordance with Bybee and Synectics models.

\section{Pyramid and cone volume according to the Bybee model (5E)}

In the first step, the researcher tried to motivate the students by defining exciting events that were related to the properties of the pyramids. Then, students were asked questions about their prior knowledge. The shapes were 
provided with the definitions of the pyramid and cone. Next, the students were asked to define the cylinder and state the cylinder volume calculation formula that they had learned previously. The responses were written on the board to expose students to the viewpoints, and then they were asked to indicate the area of various shapes. The question "what is the relationship between cone volume and cylinder volume?" was raised by the researcher. In the second phase (Explore), each group individually produced paper cylinders and cones. During the question and answer process, a number of students modified their cylinders, and this group began testing again. Meanwhile, the researcher acted as a facilitator and encouraged learners to experience, test, and the detailed review of the problem.

In the third step (Explain), the researcher asked the representative of each group to share their experiences and findings and the findings were reviewed accordingly. In the fourth step (Elaborate), a question was asked (How can the volume of the cone be calculated?) Then, the groups were requested to examine the questions individually. Similarly, the researcher allowed the students to evaluate their learning and teamwork progress in the fifth stage (Evaluate). Likewise, groups were asked to report the findings after examining the questions. Finally, assignments at different levels of learning were identified for the students.

\section{Sphere volume and sphere area according to the Synectics model}

In the first step (problem description), students were encouraged to provide information on the subject of the lesson and to describe the existing situation or what is present. The students were then divided into six groups of five and representatives were selected for each group. In addition, equipment was provided to the groups, including the colored paper, scissors, glue, a 7-cm diameter ball, a 7-cm diameter cylinder, and colored water. In the second step (direct analogy), the students were asked to find spherical patterns in the book or classroom and to describe the utility and benefits of these objects. Some examples are as follows.

Ball: Easier to move, has no angle, and this speeds up the ball.

Sky Objects: Spend the least amount of energy to achieve maximum stability. Accordingly, they are all spherical. In the third stage (intensive conflict), each group was asked to consider two faces or situations of the sphere that were in conflict. In the fourth step (direct analogy), the students were requested to provide more examples and this time they could use contrasting words to express newer examples. The most beautiful extract was as follows.

Earth: Due to the spherical nature of the Earth, there are always different hours of the day at all times (Day/night).

In the fifth step (personal analogy), students were asked to consider the following question.

Suppose you are a spherical radius $r$ that needs to be painted in two stages to become a billiard ball. In the first stage, you are thrown into a cylindrical chamber with a radius $\mathrm{r} \mathrm{cm}$ and a height of $2 \mathrm{rcm}$, filled with the desired color. "What fraction of the color does get out of the cylindrical shed?"

In step six (re-assignment review), the groups were asked to write down their findings, and the representatives of each group were requested to announce the views. Then, the views of the groups were written on the board.

The second task was to stick the stickers in circles to the radius $r$ of the manufacturer. How many stickers do you need to cover your entire surface? Finally,, the researcher summarized and completed the content by showing animations related to each section and then assigned homework to each of the students at different levels of learning. In Figures 1, 2, and 3, students' solutions in the three groups are compared for one problem.Students' solutions in the Bybee experimental group (Figure 1) show creativity in responses demonstrating deep learning and strong mental skills. According to the gained experiences in the class, students used a simple and short answer rather than a detailed answer. The conical volume was $1 / 3$ of the cylinder volume equal to the regular height. 


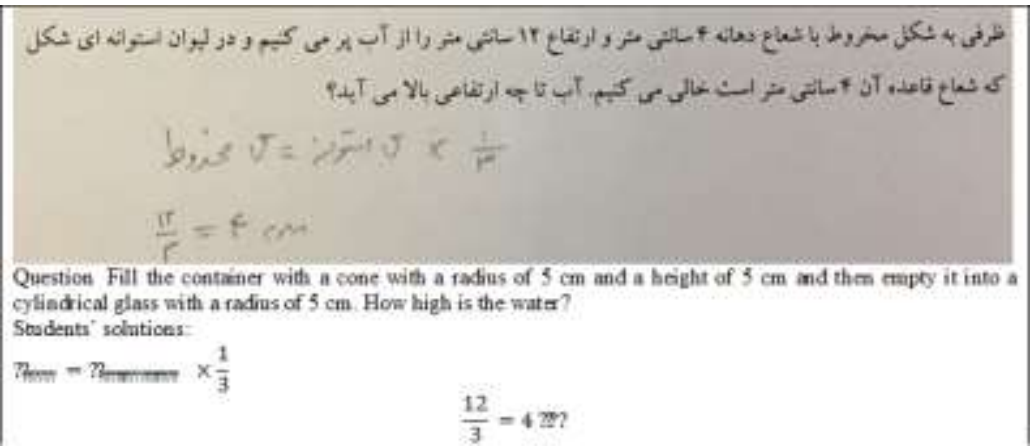

Fig.1: Students' solutions in the Bybee group

The solution of the Synectics group (Figure 2) demonstrates the creativity in writing and expanding the visibility of learners' analytics capability. By simplifying the formula for this problem, the cylinder height was calculated by equating the volume of the cone and cylinder.

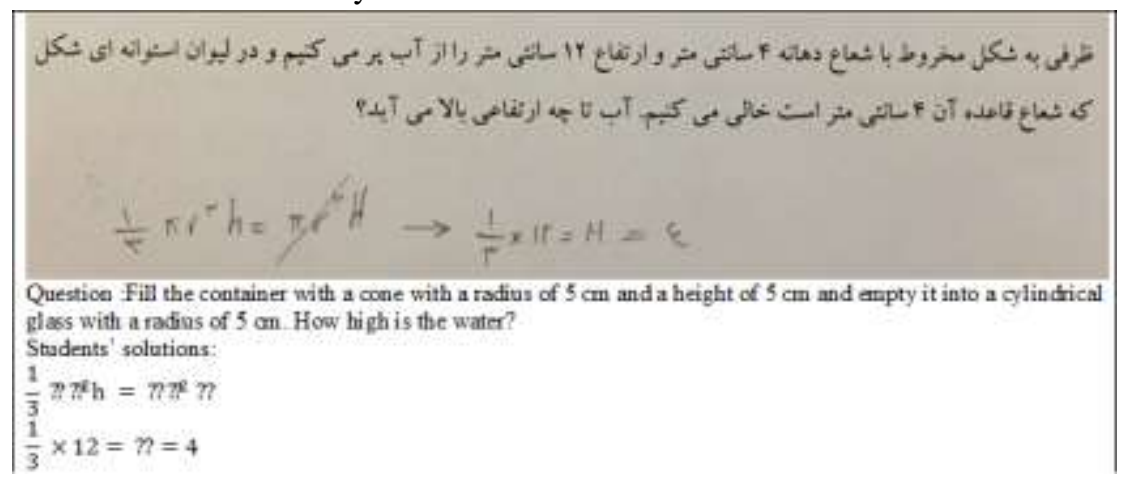

Fig.2: Students' solutions in the Synectics group

The control group's solution (Figure 3) represents a poor understanding of geometric volumes, a misunderstanding of the relationship between the variables, and inaccuracy in reasoning and conceptualization. Despite the knowledge of volume calculation formulas, the strategy was not properly used, and students considered the elevation of the liquid level in the cone rather than the height of the water in the cylinder.

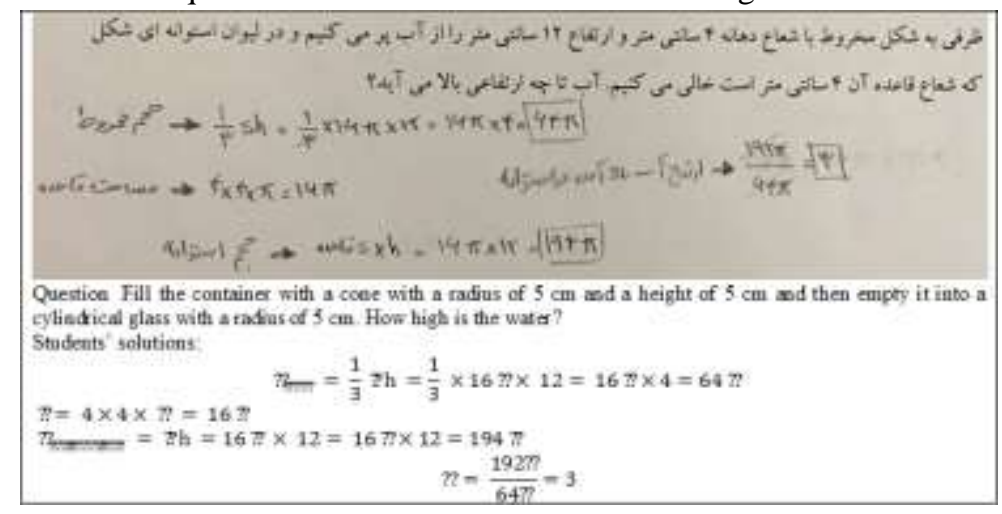

Fig.3: Students' solutions in the control group

\section{RESULTS}

In Tables 1 to 3, the mean and standard deviation were used to test descriptive statistics. The findings showed that the mean scores in the pre-tests were the same and the groups were scientifically similar while the mean scores in the post-test scores of Bybee and Synectics groups in performance tests, creativity, and creative solution were more compared to the control group. Additionally, the highest amount of deviation in creativity, performance, and creative solving tests was related to the pre-test of the Bybee group.

In the control group, students had unresolved problems. More precisely, they had difficulties in drawing, calculations, and arguments due to the lack of an accurate picture of geometric surfaces. In congruent triangles, they sometimes did not recognize the sides or angles or did not consider the midline angle in the "two sides 
between" and "two angles between" positions. In addition,, they were less confused on questions regarding which triangles were raised individually. Due to the lack of basic information, the students used the formulas of area and volume interchangeably or wrote the formulas more or less. Sometimes, they did not understand the hypothesis and induction correctly. In other words, the students did not have the right strategy using the cohesive states. Using the congruent form, students did not have the right strategy. At first, they wrote all of the data and then decided on which congruent form to use accordingly.

Table 1: Descriptive Statistics of the Creativity Test

Note. N: Number; SD: Standard deviation.

\begin{tabular}{|l|l|l|}
\hline Characteristics & N & Mean (SD) \\
\hline Pretest control & 30 & $76.90(11.77)$ \\
\hline Posttest control & 30 & $77.43(11.74)$ \\
\hline Pretest Bybee & 30 & $77.33(14.92)$ \\
\hline Posttest Bybee & 30 & $88.33(12.16)$ \\
\hline Pretest synectics & 30 & $80.10(12.39)$ \\
\hline Posttest synectics & 30 & $89.20(11.93)$ \\
\hline
\end{tabular}

Table 2: Descriptive Statistics of Creative Solving Test

Note. N: Number; SD: Standard deviation.

\begin{tabular}{|l|l|l|}
\hline Characteristics & N & Mean (SD) \\
\hline Pretest control & 30 & $53.43(7.48)$ \\
\hline Posttest control & 30 & $54.13(8.43)$ \\
\hline Pretest Bybee & 30 & $54.43(8.89)$ \\
\hline Posttest Bybee & 30 & $62.16(7.74)$ \\
\hline Pretest synectics & 30 & $56.20(6.35)$ \\
\hline Posttest synectics & 30 & $61.40(6.78)$ \\
\hline
\end{tabular}

Table 3: Descriptive Statistics of Performance Test

Note. N: Number; SD: Standard deviation

\begin{tabular}{|l|l|l|}
\hline Characteristics & N & Mean (SD) \\
\hline Pretest control & 30 & $13.44(3.50)$ \\
\hline Posttest control & 30 & $13.86(2.69)$ \\
\hline Pretest Bybee & 30 & $13.45(4.63)$ \\
\hline Posttest Bybee & 30 & $16.61(2.86)$ \\
\hline Pretest synectics & 30 & $13.19(4.19)$ \\
\hline Posttest synectics & 30 & $15.92(2.47)$ \\
\hline
\end{tabular}

Kolmogorov-Smirnov test was used to evaluate the normality of the data and the findings showed that the scores in all groups were normal $(\mathrm{P}>0.05)$ confirming the use of parametric tests.

Table 4: ANCOVA Results for the Effect of Bybee Model on Creativity, Creative Solving, and Performance

\begin{tabular}{|l|l|l|l|l|l|}
\hline \multicolumn{7}{|l|}{ Tests of Between-Subjects Effects } \\
\hline Dependent variable: VAR00004 & & & & \\
\hline Source & Type III Sum of Squares & df & Mean Square & F & Sig. \\
\hline Corrected model & $84499.420^{\text {a }}$ & 56 & 1508.918 & 62.573 & 0.000 \\
\hline Intercept & 5438.781 & 1 & 5438.781 & 225.540 & 0.000 \\
\hline Group & 379.429 & 1 & 379.429 & 15.735 & 0.000 \\
\hline VAR00003 & 7350.216 & 55 & 133.640 & 5.542 & 0.000 \\
\hline Error & 795.777 & 33 & 24.114 & & \\
\hline Total & 364575.000 & 90 & & & \\
\hline Corrected total & 85295.197 & 89 & & & \\
\hline a. R Squared = 0.991 (Adjusted R Squared =0.975) & & \\
\hline
\end{tabular}

Note. ANCOVA: Analysis of covariance. 
According to data in Table 4, there is a significant difference between the pretest and posttest scores of creativity, creative solving, and performance $(\mathrm{P}=0.000)$. These findings support the positive effect of using Bybee in participants' creativity, creative solving, and performance.

Table 5: ANCOVA Results for the Effect of the Synectics Model on Creativity, Creative Solving, and Performance

\begin{tabular}{|l|l|l|l|l|l|}
\hline \multicolumn{2}{|l|}{ Tests of Between-Subjects Effects } \\
\hline Dependent variable: VAR00002 & & & & \\
\hline Source & Type III Sum of Squares & df & Mean Square & F & Sig. \\
\hline Corrected model & $87386.114^{\mathrm{a}}$ & 65 & 1344.402 & 86.680 & 0.000 \\
\hline Intercept & 2139.170 & 1 & 2139.170 & 137.922 & 0.000 \\
\hline Group & 78.000 & 1 & 78.000 & 5.029 & 0.034 \\
\hline VAR00001 & 6701.113 & 64 & 104.705 & 6.751 & 0.000 \\
\hline Error & 372.240 & 24 & 15.510 & & \\
\hline Total & 365286.188 & 90 & & & \\
\hline Corrected total & 87758.353 & 89 & & & \\
\hline a. R Squared = 0.996 (Adjusted R Squared = 0.984) & & \\
\hline
\end{tabular}

Note. ANCOVA: Analysis of covariance.

Based on the obtained data in Table 5, there is a significant difference between the pretest and posttest scores of creativity, creative solving, and performance $(\mathrm{P}=0.034)$. Considering that the mean score of the posttest was significantly higher, synectics had a positive effect on students' creativity, creative solving, and performance.

Table 6: ANCOVA Results for the Effect of the Traditional Model on Creativity, Creative Solving, and Performance

\begin{tabular}{|l|l|l|l|l|l|}
\hline \multicolumn{5}{|l|}{ Tests of Between-Subjects Effects } \\
\hline Dependent variable: VAR00006 & & & & \\
\hline Source & Type III Sum of Squares & df & Mean Square & F & Sig. \\
\hline Corrected model & $68139.494^{\mathrm{a}}$ & 58 & 1174.819 & 191.342 & 0.000 \\
\hline Intercept & 1298.458 & 1 & 1298.458 & 211.479 & 0.000 \\
\hline Group & 0.245 & 1 & 0.245 & 0.040 & 0.843 \\
\hline VAR00005 & 7528.678 & 57 & 132.082 & 21.512 & 0.000 \\
\hline Error & 190.336 & 31 & 6.140 & & \\
\hline Total & 279838.375 & 90 & & & \\
\hline Corrected total & 68329.831 & 89 & & & \\
\hline a. R Squared $=0.997$ (Adjusted R Squared =0.992) & & \\
\hline
\end{tabular}

Note. ANCOVA: Analysis of covariance.

As indicated in Table 6 , the level of significance is 0.83 , implying that the difference between the pretest and posttest scores of creativity, creative solving, and performance was not significant. Therefore, the scores in the posttest demonstrated no significant change in the control group. In other words, Bybee and Synectics methods performed better compared to the traditional one, and the use of these two methods had positive impacts on students' performance and creative problem-solving in geometry.

\section{DISCUSSION AND CONCLUSION}

In general, using traditional methods in geometry teaching prevents students from the practical observation of the content thus they prefer to resort to inappropriate methods such as memorizing the definitions of the geometry, which impedes their level of geometric thinking. The applied teaching methods are directly related to the growth of students' creativity and creativity can be enhanced through instruction among the students. Using these methods while teaching, students explore the subject matter without limitations and are involved in the solution process, which increases the possibility of creativity in students.

The present study attempted to investigate the effects of Bybee and Synectics methods on the creativity, creative problem-solving, and performance of ninth-grade students in geometry. To this end, the pretest scores of creativity, creative problem-solving, and performance of all three groups were identified and the findings revealed that experimental groups and the control group were at the same level. After training based on Bybee 
and Synectics models and comparing the findings of pretests with posttests, it was found that these models outperformed the traditional method of instruction in geometry regarding students' creativity, creative problemsolving, and performance. The Bybee model is effective in production, control, generalization, and deep learning. The students collaborated in the groups when using the Bybee model and directly gained the findings of each experience and built their knowledge. In addition, they participated in the activities with interest, paid more attention, and had a better understanding of the details. Further, their mind skills grew stronger so that they were not bound by the rules and used innovative ideas to solve the problems. Eventually, using previous materials as a basis for new materials reduced the teaching time.

Reviewing ANCOVA test results in Table 4 showed that the Bybee model played a role in enhancing students' creativity, creative problem-solving, and performance.

These findings are in congruent with those of several studies such as Tezer and Kamer (2017), Sacita et al. (2015), Demircioglu and Cagatay (2014), and Karsli and Ayas (2014) based on the Bybee method.

Moreover, the use of analogies made students face more tangible problems with geometry and their imagination levels were strengthened regarding paying attention to the relationships in the Synectics group. It is believed that these models would reduce teaching time. In the Synectics model, the analogies applied in previous concepts were used to teach new concepts. Additionally, using diverse solutions by the students was one of the most beneficial findings of this study.

Based on ANCOVA test findings in Table 5, the Synectics model increased students' creativity, creative problem-solving, and performance .In explaining the development of problem-solving skills and creative thinking using the Synectics model, the findings of the present study corroborate with those of Ayme and Haqqani (2012) and Abed et al. (2015). Similarly, the findings of the current study are in line with those of Ahmad Khan and Mahmood (2017), as well as Arifiyanti and Wahyuningish (2015) that examined the role of Synectics modeling in students' understanding of geometrical concepts. Based on their reports, the level of students instructed by the Synectics method significantly increased in terms of comprehending abstract concepts and the knowledge of learning skills. In addition, the level of learners who were trained according to the Synectics model increased dramatically. The evaluation of ANCOVA test findings (Table 6) showed that the traditional method failed to increase creativity, creative solution, and student performance. Based on the findings of this study and those of other studies, Bybee and Synectics models outperformed the control group in terms of innovation creativity, creative problem-solving, and students' performance in geometry. Accordingly, it is recommended that these methods should be used in other lessons and levels of proficiency across time. Further, other tools such as interviews and observation, and the like can be applied in future research in order to increase the validity of the study. Furthermore, it is suggested that in-service teachers be familiarized with Bybee and Synectics methods and use them while teaching. Thus, the context for applying these methods can be prepared for the teachers. Moreover, creativity workshops in geometry can be held for students by using this model. Finally, the education system can focus on innovation and creativity in order to achieve this goal by designing teaching methods that are appropriate for the students.

\section{REFERENCES}

1. Abadi, J. (1993). The novelty and methods of its measuring. Journal of Psychological Research, 3 (72), 46-54.

2. Abed, S., Davoudi, A. H., \& Hoseinzadeh, M. (2015). The effect of synectics pattern on increasing the level of problem-solving and critical thinking skills in the students of Alborz province. WALZA Journal, 31 (1), 110-118.

3. Acisli, S., Yalem, S. A., \& Turgut, Ü (2011). An evaluation of activities designed in accordance with the 5E model by would-be science teachers. Procardia Social and Behavioral Sciences 15, 708-71.

4. Ahmad Khan. A., \& Mahmood, N. (2017). The role of the Synectics model in enhancing students' understanding of geometrical concepts. Journal of Research and Reflections in Education. 2 (11), 253264.

5. Aiamy. M., \& Haghani, F. (2012). The effect of synectics and brain storming on $3^{\text {rd }}$ grade students' development of creative thinking on science. Procardia Social and Behavioral Sciences, 47, 610-613. 
6. Arifiyanti, S. F., \& Wahyuningish, S. (2015). Using integrated analogy in physics education to building the concept of representation: The way to be great inventor. Proceeding of International Conference on Research, Implementation, and Education of Mathematics and Science, Indonesia: Yogyakarta State University, 17-19 May 2015.

7. Basador, M. S., Graen, G. B., \& Green, S. G. (1982). Training in creative problem solving: Effect on ideation and problem finding in an applied research organization. Organizational Behavior and Human Performance, 30 (1), 41-70.

8. Blissett, S. E., \& McGrath, R. E. (1996). The relationship between creativity and interpersonal problem-solving skills in adults. The Journal of Creative Behavior, 30 (3), 173-182.

9. Bybee, R. W. (2009). The BSCS 5E instructional model and 21st century skills. Colorado Springs, CO: BSCS.

10. Demircioglu, G, \& Cagatay, G. (2014). The effect of laboratory activities based on 5E model of constructivist approach on 9th grade students' understanding of solution chemistry. ProcediaSocial and Behavioral Sciences, 116, 3120-3124.

11. Fyfe, E. R., McNeil, N. M., \& Borjas, S. (2015). Benefits of "concreteness fading" for children's mathematics understanding. Learning and Instruction, 35, 104-120.

12. Gallenstein, N. (2013). Concept mapping for learners of all ages. Journal for Educators, Teachers, and Trainers, 4 (1), 59-72.

13. Gordon, W. J. J. (1961). The development of creativity. In Elvadine R. S. (2007). Reaching Students through Synectics: A creative solution. Retrieved from http://www.ellieseligmann.com/essays/synec tics_seligmann.pdf

14. Heid, K. (2008). Creativity and imagination: Tools for teaching artistic inquiry. Art Education, 61 (4), 40-46.

15. Joyce, B., Weil, M., \& Kalhon, E. (2013). Teaching patterns. Translated by: Behrangi, M.R., Tehran: Kamal Tarbiat.

16. Karimi, S., Shahvarani, A., \& Haghverdi, M. (2019). The role of problem-based mathematics teaching according to the Kirkpatrick's model on problem-solving performance of mathematics teachers. Journal for Educators, Teachers, and Trainers, 10 (1), 12-26.

17. Karsli, F., \& Ayas, A. (2014). Developing a laboratory activity by using $5 E$ learning model on student learning of factors affecting the reaction rate and improving scientific process skills. Procedia-Social and Behavioral Sciences, 143 (2014), 663-668.

18. McLaren, D. (2010). Does theory have any point? Mathematics in School for Secondary and College Teachers of Mathematics, 39 (5), 2-9.

19. Runisah Hemen, T., \& Dahlan, J. A. (2016). The enhancement of students' creative thinking skills in mathematic through the $5 \mathrm{E}$ learning cycle with metacognitive technique. International Journal of Education and Research, 4 (7), 347-360.

20. Shabani, H. (2016). Educational Skills of teaching methods and techniques. Twentieth edition, Tehran: SAMT Publication.

21. Suciati, A. Vincentrisia, I. (2015). Application of learning cycle model (5E) learning with chart variation toward students' creativity. Journal Pendidikan IPA Indonesia, 4 (1), 56-66.

22. Tezer, M., \& Cumhur, M. (2017). Mathematics through the $5 \mathrm{E}$ instructional model and mathematical modelling: The geometrical objects. Eurasia Journal of Mathematics, Science, and Technology Education, 13 (8), 4789-4804.

23. Walia, P. (2012). Effect of $5 \mathrm{E}$ instructional model on the mathematical creativity of students. Journal of Golden Research Thoughts, 1 (10), 1-4.

24. Zare, H., Imaniifar, H. R, Mostafaei, A., \& Brothers, M. (2014). Validation and functional structure of the creative problem-solving test. Journal of Innovation and Creativity in Humanities, 3 (4),127-146. 